\title{
GRAHAM ODDIE
}

\section{A REFUTATION OF PEIRCEAN IDEALISM}

Some years ago I arrived at Otago University as a freshman, intending to study law and to become a lawyer. My Hall of Residence thoughtfully assigned me a roommate whose intention it also was to study law and become a lawyer. My roommate had already spent a year working in a lawyer's office, and so he was better informed than I was about the daily practice of the law. The evening before registration he told me all about the Fencing Act - not the laws governing dueling, which might have been interesting, but the laws governing the boundaries between suburban neighbours. The idea of spending my life thinking about such matters didn't thrill me, and I resolved to withdraw from law and sign up as a philosophy major the following day. To make the change I had to visit the Head of the majoring department and ask him to sign the necessary papers. That is when I first met the young Alan Musgrave, Professor of Philosophy.

I have to confess that at that meeting Professor Musgrave did not inspire me, or even encourage me to pursue philosophy. He intimated I was doing something a bit foolish - passing up the chance for a degree (and a lucrative career) in law, for a degree (and almost certain unemployment) in philosophy. Professor Musgrave's reaction must have given me pause for thought - why else would I remember it more than thirty years later? But my next encounter with the Professor was in the first lecture of his Introduction to Philosophy course - and that was a very different experience. I can still see him striding up and down at the front of the lecture hall, talking loudly without lecture notes in his accent from Manchester, punctuating sundry claims with a belligerent 'Yes?' that more or less demanded agreement.

Alan's excellent lectures were highly entertaining, enormously informative, amazingly clear, totally lacking in obfuscation, and bracingly partisan. Unlike many of his contemporaries in the profession, he was adamant that the discipline of philosophy had made real progress, that philosophical conjectures could be, and often were, refuted. It was obvious when Alan thought a philosophical conjecture had been successfully refuted. It was also obvious that he was a passionate advocate for a brand of common-sense realism mixed in with a healthy dose of skepticism (which he called fallibilism). This was heady stuff for a seventeen year old who knew absolutely nothing. By the time that first lecture was over I was hooked on whatever it was the absurdly young professor was doing up there - philosophy_and I have been ever since.

Musgrave's introduction to philosophy had a powerful and lasting effect on me. But more than the content of his philosophy, the way Alan did philosophy is what

1

C. Cheyne \& J. Worrall (eds.), Rationality and Reality, 1-7.

(C) 2008 Kluwer Academic Publishers. Printed in the Netherlands. 
intrigued me. I admire, perhaps now more than ever, the virtues I saw dramatically exhibited in that first series of lectures. I was reminded of these virtues while rereading two of Musgrave's sorties against his bête noir-contemporary idealism (Musgrave 1997 and 1999). And the fruit of that reminder is this paper-a rather ridiculously simple argument against a class of theories which Musgrave finds particularly irksome. These theories all embrace, in one form or another, the Peircean idea that truth is whatever our best scientific theory (or theories) endorse in the limit of inquiry.

My argument has a number of famous predecessors, one of which Musgrave himself outlines in his attack on epistemic theories of truth (Musgrave 1997). He attributes the argument to Timothy Williamson, but in fact it has a long and illustrious lineage which can be traced back to a 1963 article in the Journal of Symbolic Logic by Fitch. (For a good summary of this history see the on-line encyclopedia article by Brogaard and Salerno. For an application of a Fitch-style argument to the issue of traditional idealism, see Oddie 2000.)

Many philosophers are, as Musgrave puts it, 'certainty freaks'. They cannot tolerate the possibility that we can't really be justifiably certain about anything much of interest, or that most of what passes for knowledge is fallible. Musgrave has argued that idealism, in all of its various guises, is at bottom an attempt to close the certainty gap; an attempt to guarantee that what we experience, or what we believe, or what science proclaims, is the way the world really is. But the gap is closed by metaphysical fiat - the world is declared to be nothing more than the sum total of what we experience, or believe, or what science puts its stamp of approval on.

The range of idealist theories that Musgrave is most exercised about are those in the last category - those according to which endorsement by our best scientific theory is not merely an indicator, but is rather constitutive, of the real. The true is what our best science endorses.

Science changes, of course, and our best scientific theory at one particular time might be different from our best scientific theory at some other time. Thus what our best science endorses will also change. Because of this we cannot identify truth with what is endorsed by our best scientific theories simpliciter. For a start, no-one thinks that science has had its final say, and for another it would render time-independent propositions (like the laws of nature) temporally fickle affairs. This is where the Peircean limit theory of truth comes to the rescue: the truth is not necessarily what we find to be epistemically acceptable in the light of the current crop of theories, but rather what we will (or would) find epistemically acceptable in the light of theories we will (or would) hold at the limit of the scientific endeavour.

I say 'theories' rather than 'theory' for two reasons. The first is that there may be two rival theories in a domain, both of which endorse a large number of common propositions, but which also disagree over others. Even if we cannot rank one of the theories above the other then the propositions they agree on should still be deemed epistemically acceptable. The second is that different theories might cover different domains, and there might be some propositions which are the consequences of the best theories, taken together, governing different domains. In that case we would also want such propositions to be deemed epistemically acceptable. 
Musgrave marshals a range of refutations of Pericean idealism. In particular, he gives a summary of a Fitch-style argument against the positivist thesis that if a proposition is true then it is knowable. With a couple of very weak principles governing possibility and knowledge we can show that this entails that if $a$ proposition is true then it is known. And that is clearly absurd.

It will be useful to sketch the Fitch-style argument and consider its relevance to Peircean idealism. Where $\mathrm{Kp}$ is short for $p$ is known, and $\mathrm{Pp}$ is short for $p$ is possible, then we can abbreviate $p$ is knowable (that is, it is possible for $\mathrm{p}$ to be known) to PKp. The positivist thesis that all truths are knowable is, as Musgrave notes, not supposed to be merely contingently true. It is supposed to be a matter of necessity. Of necessity, any true proposition is knowable. We can state the thesis succinctly thus (where $\Rightarrow$ is logical entailment).

$$
\text { Positivist thesis: } \quad \text { For all } \mathrm{p}, \mathrm{p} \Rightarrow \mathrm{PKp} \text {. }
$$

A proposition cannot be known unless it is true. Again, this principle (call it facticity for $K$ ) is not a contingent feature of knowledge. That $\mathrm{p}$ is known entails that $\mathrm{p}$ is true.

Facticity for $\mathrm{K}: \quad$ For all $\mathrm{p}, \mathrm{Kp} \Rightarrow \mathrm{p}$

Finally, we assume that knowledge of a conjunction implies knowledge of each conjunct. Call this Distribution for K.

$$
\text { Distribution for } K: \quad \text { For all } p, q, \quad K(p \& q) \Rightarrow K p \& K q
$$

Finally, to make all our assumptions explicit we need the modal principle that if a proposition logically entails a contradiction then it isn't possible for it to be true. Note that any concept of possibility, even logical possibility, will deliver this principle.

$$
\text { Impossibility principle: } \quad \text { For all } \mathrm{p} \text { and } \mathrm{q},(\mathrm{p} \Rightarrow(\mathrm{q} \& \sim \mathrm{q})) \Rightarrow \sim \mathrm{Pp} \text {. }
$$

Here is one way of running the Fitch-style argument. For the sake of a reductio we start with an intriguing assumption. Assume that for some arbitrary proposition $p$ the following is known: that $\mathrm{p}$ is true and $\mathrm{p}$ is not known to be so, (i.e. $\mathrm{K}(\mathrm{p} \& \sim \mathrm{Kp})$ ). We then show that this assumption entails a contradiction. Consequently it is not possible that $\mathrm{K}(\mathrm{p} \& \sim \mathrm{Kp})$. So $\sim \mathrm{PK}(\mathrm{p} \& \sim \mathrm{K} p))$ for any proposition $\mathrm{p}$. According to the positivist thesis, if (p\& Kp) were true then so too would $P K(p \& \sim K p)$. But we have

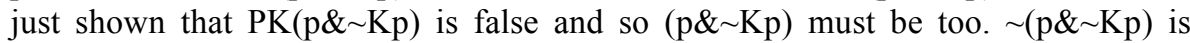
however, logically equivalent to the thesis we want to prove: that for any $p$, if $p$ is true then $\mathrm{p}$ is known.

It may be helpful to lay out this proof formally. Where a step is a matter of undisputed logical inferences I cite 'logic' as the justification. 
1. $\mathrm{K}(\mathrm{p} \& \sim \mathrm{Kp})$

2. $\mathrm{K} p \& \mathrm{~K} \sim \mathrm{Kp}$

3. $\mathrm{Kp}$

4. $\mathrm{K} \sim \mathrm{Kp}$

5. $\sim \mathrm{Kp}$

6. $\mathrm{K}(\mathrm{p} \& \sim \mathrm{Kp}) \Rightarrow \mathrm{Kp} \& \sim \mathrm{Kp}$

7. $\sim \mathrm{PK}(\mathrm{p} \& \sim \mathrm{Kp})$

8. $\mathrm{p} \& \sim \mathrm{Kp} \Rightarrow \mathrm{PK}(\mathrm{p} \& \sim \mathrm{Kp})$

9. $\sim(\mathrm{p} \& \sim \mathrm{Kp})$

10. $\mathrm{p} \Rightarrow \mathrm{Kp}$
Assumption

1, Distribution

2, logic

2 , logic

4, Facticity

$1-5$, logic

6, Impossibility

Positivist thesis

7,8 , logic

9 , logic

As noted, step 9 is tantamount to the claim that if $\mathrm{p}$ is true then it is known to be so. But since the principles in the derivation up to and including 9 are purely logical, we have established more than the mere truth of $\sim(\mathrm{p} \& \sim \mathrm{Kp})$. We have established that it's logical truth. (The only non-logical assumption is discharged at step 6.) Thus we have established that, of necessity, if $p$ is true then $p$ is known. That is to say, that a proposition $\mathrm{p}$ is true logically entails that $\mathrm{p}$ is known. And that is logically absurdunless an omniscient being exists of logical necessity. (A new ontological argument might be culled from positivism!)

If the positivist doctrine were the weaker claim that all truths are knowable as a matter of contingent fact, then all we could derive is the weaker conclusion that if a proposition is true then it is known in fact. But that is also absurd-unless, perhaps, an omniscient being happens to exist. (Positivists would not rejoice to find they have provided an argument for the merely contingent truth of theism.)

Can this Fitch-style strategy be turned against the Peircean idealist directly? The Peircean idealist holds that in the limit science will (or would) reveal all truths, and that does seem to entail that all truths are knowable. However, I would like a more direct refutation of Peircean idealism, one that uses only principles that the Peircean explicitly affirms or which everyone would accept. One reason for seeking out another argument is that even if we can show that the Peircean is committed to the positivist principle, the Fitch reductio is by no means uncontroversial. Many of these criticisms are without merit (see Oddie 2000). However, the distribution principle for knowledge does seem a little bit suspect. For together with just one other equally plausible principle of knowledge, distribution entails the closure of $\mathrm{K}$ under entailment. Closure of $\mathrm{K}$ under entailment is the claim that if a proposition is known then all of its logical consequences are also known.

Closure for K:

$$
(\operatorname{Kp} \&(p \Rightarrow q)) \Rightarrow K q
$$

The extra principle which in conjunction with distribution entails closure is the principle of equivalence. (Let $\Leftrightarrow$ be mutual entailment, or equivalence.)

Equivalence for $K: \quad(p \Leftrightarrow q) \Rightarrow(K p \Leftrightarrow K q)$. 
If we think of propositions as individuated by their truth conditions, then to know a proposition is to know that a certain truth condition is satisfied. Thus if $p$ is known to be true, then any other proposition with the very same truth condition is also known to be true (even if we don't know we know it).

We can easily prove closure from distribution and equivalence:

\begin{tabular}{|c|c|}
\hline 1. $\mathrm{Kp} \&(\mathrm{p} \Rightarrow \mathrm{q})$ & Assumption \\
\hline 2. $\mathrm{Kp}$ & 1, logic \\
\hline 3. $\mathrm{p} \Rightarrow \mathrm{q}$ & 1, logic \\
\hline 4. $p \Leftrightarrow(p \& q)$ & 3 , logic \\
\hline $\mathrm{K}(\mathrm{p} \& \mathrm{q})$ & 2,4 Equivalence \\
\hline 6. $\mathrm{Kq}$ & 5, Distribution \\
\hline 7. $(\operatorname{Kp} \&(p \Rightarrow q)) \Rightarrow K q$ & $1-6, \operatorname{logic}$ \\
\hline
\end{tabular}

Closure for knowledge does seem a bit dubious. The fact that a proposition is known does not seem to entail that all its logical consequences are known. Since closure is a consequence of distribution and equivalence, that doubt spreads over the conjunction of the latter two principles.

So, it would be nice to have an argument against Peircean idealism that did not get us bogged down in debates about closure for knowledge. But as we will see, we cannot simply take over the Fitch argument utilising the preferred Peircean concepts (the concepts of truth in the limit and of epistemic acceptability), because these do not necessarily obey the same principles as knowledge and possibility.

Let us abbreviate the claim proposition $p$ is epistemically acceptable according to our best scientific theories to Ep. I take it that propositions are not eternal, that they can change their truth values over time. And it is clear that the proposition Ep in particular is not time-independent. Ep can be false at one moment, true at a later moment, and perhaps false again later on. Further, Ep might be true at one moment while $E \sim p$ is true at another later moment. (We can even entertain the possibility that our best theories are jointly contradictory (perhaps unbeknownst to us), so that Ep and $E \sim p$ may both be true at a single moment.) Most importantly for our purposes, however, is that there is no principle of facticity for E. Ep clearly does not entail p. That is the main reason we cannot simply apply the Fitch strategy here.

Peircean theories make use of the idea of Ep being true 'in the limit'. The idea of limiting truth does not, however, have to be confined to propositions about epistemic acceptability. It is a quite general notion. But what exactly does it mean to say of a possibly changing proposition that it is true 'in the limit'? There is an obvious answer to this, as well as a slightly less obvious one. First, the obvious answer. Suppose a proposition $p$ routinely changes its truth value. At $t, p$ is true; at $t+, p$ switches its truth value to false; at $\mathrm{t}++, \mathrm{p}$ switches back to true ... and so on, forever, at either regular or irregular intervals. It would seem problematic to say in this case that $p$ is either true or false in the limit. Suppose, on the other hand, that after switching like this for some time, $\mathrm{p}$ becomes true and remains true thereafter. Then it does seem entirely appropriate to say that $\mathrm{p}$ is true in the limit. So if a proposition becomes true and stays true permanently, then it is true in the limit. 
There is another type of case in which we may be tempted to say that $p$ is true in the limit, even though p's truth value keeps switching, and never settles down. Suppose the intervals during which $\mathrm{p}$ is false get relatively shorter and shorter, so that the ratio of the sum of the lengths of intervals during which $p$ is false to total elapsed time (measuring both from some given moment), tends to 0 as time passes. Is $p$ true 'in the limit'? There is clearly a sense in which $p$ tends towards permanent truth even though it never quite makes it to permanent truth. Satisfying the more obvious notion of limiting truth entails satisfying the less obvious one. For our purposes we can either work with the more obvious idea that $p$ eventually settles on truth permanently, or we can work with the less obvious notion, that $\mathrm{p}$ tends towards permanent truth. In any case, let's abbreviate $p$ is true in the limit to Lp.

The Peircean says that $\mathrm{p}$ is true if and only if in the limit $\mathrm{p}$ is epistemically acceptable, or endorsed by our best scientific theories. But, as Musgrave notes, the Peircean is not simply committed to this theory as a contingent truth. He is not just asserting that, as a matter of contingent fact, science will unearth all and only the truths. Rather, this is an account of the nature of truth, it is supposed to be true of necessity. In other words, where $\Leftrightarrow$ is logical equivalence Peircean idealism can be summarised thus:

$$
\text { Peircean idealism: } \quad \mathrm{p} \Leftrightarrow \text { LEp }
$$

Suppose $\mathrm{p}$ is true in the limit, and $\mathrm{p}$ entails $\mathrm{q}$. Then whenever $\mathrm{p}$ is true $\mathrm{q}$ is also true. So, on the simple and obvious account of limiting truth - as eventual permanent truth $-\mathrm{q}$ must also be true in the limit. That is to say, $\mathrm{L}$ is closed under entailment. But this will also hold on the less obvious account of limiting truth as tendency to permanence. Indeed, whatever account we give of limiting truth, it should be closed under entailment $(\Rightarrow)$.

$$
\text { Closure for L: } \quad(\operatorname{Lp} \&(p \Rightarrow q)) \Rightarrow \text { Lq. }
$$

Suppose that at some stage of scientific inquiry, $\mathrm{p}$ is epistemically acceptable according to the best theories at the time: Ep is true. Is the proposition Ep itself epistemically acceptable at that time? If Ep is true our best scientific theories tell us we should accept $\mathrm{p}$. But then, in telling us that, they thereby endorse Ep. So, in the light of those theories we should accept not only p itself, we should also accept Ep. But to say that we should accept Ep in the light of those theories is to say that EEp is true. Briefly, if Ep then EEp. Again, there is nothing contingent about this, it is a matter of necessity. So we have the EE principle.

$$
\text { EE principle: } \quad \mathrm{Ep} \Rightarrow \mathrm{EEp} \text {. }
$$

Given these principles we can demonstrate that every truth is not merely epistemically acceptable in the limit of scientific inquiry, but rather that it is epistemically acceptable now, period: 
For any proposition $\mathrm{p}, \mathrm{p} \Rightarrow \mathrm{Ep}$.

Proof:

$\begin{array}{ll}\text { 1. } \mathrm{p} & \text { Assumption } \\ \text { 2. } \mathrm{p} \Rightarrow \mathrm{LEp} & \text { Peircean idealism } \\ \text { 3. LEp } & 1,2 \text { logic } \\ \text { 4. } \mathrm{Ep} \Rightarrow \mathrm{EEp} & \text { EE Principle } \\ \text { 5. LEEp } & 3,4 \text { Closure } \\ \text { 6. LEEp } \Rightarrow \text { Ep } & \text { Peircean idealism } \\ \text { 7. } \mathrm{Ep} & 5,6 \text { logic } \\ \text { 8. } \mathrm{p} \Rightarrow \mathrm{Ep} & 1-7, \text { logic }\end{array}$

Suppose we weaken Peircean idealism to the contingent claim that in fact whatever is true will be epistemically acceptable in the light of scientific inquiry in the limit. Then, our conclusion is merely the contingent claim that if $\mathrm{p}$ is true then it is now epistemically acceptable according to scientific theory. Or; conversely, if a proposition is not endorsed by current science then it is false. That's implausible.

You might feel that this cannot be right, even if you cannot pinpoint an error. You might feel that a philosophical position as subtle and widespread as Peircean idealism cannot be refuted as simply as this. You may be right that there is an error lurking in my refutation of Peircean idealism. But ever since my second encounter with Alan Musgrave I have been confident that refutations in philosophy are indeed possible, and that some are actual. Maybe this is one of those.

\section{REFERENCES}

Brogaard, B. and Salerno, J. 'Fitch's Paradox of Knowability.' Stanford On-Line Encyclopedia of Philosophy, http://plato.stanford.edu/entries/fitch-paradox/

Fitch, F. (1963) 'A Logical Analysis of Some Value Concepts.' The Journal of Symbolic Logic 28: 13542.

Musgrave, A. (1997) 'The T-Scheme plus Epistemic Truth equals Idealism.' Australasian Journal of Philosophy 75: 490-496.

Musgrave, A. (1999) 'Conceptual Idealism and Stove's Gem.' in M.L. Dalla Chiara et al. (eds) Language, Quantum, Music. Dordrecht: Kluwer.

Oddie, G. (2000) 'Permanent Possibilities of Sensation.' Philosophical Studies 98: 345-359. 